\title{
Assessing cognitive learning strategies: A global study of Spanish learners
}

\author{
Di Carlo, Sergio $\square$
}

National University of Córdoba,Argentina (contact@sergiodicarlo.com)

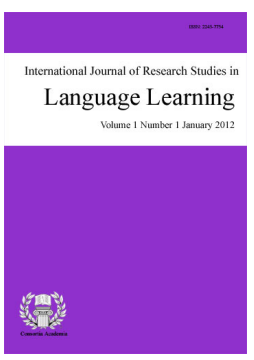

ISSN: $2243-7754$ Online ISSN: 2243-7762

\section{Abstract}

This article identifies and describes the types of cognitive language learning strategies used by learners of Spanish. Sample consisted of 665 participants, adult learners of Spanish from 60 universities and institutions. Data were collected with a self-completion multi-scale online survey. Descriptive statistical techniques (frequency distributions, arithmetic mean, standard deviation and percentage computing) were applied in analysis to achieve the objectives. Five theoretical categories were adopted to classify strategies according to their predominant function: classification, preparation, association, elaboration and transfer-practice. Thirty strategies were identified as the most used by the majority and all the five categories were present among these most used strategies. Data analysis confirmed different degrees of perceived usefulness on potential strategies. These findings suggest that different functional actions contribute to the comprehensive development of communicative competence.

Keywords: cognitive strategies; foreign language; second language acquisition; self-assessment; Spanish 


\section{Assessing cognitive learning strategies: A global study of Spanish learners}

\section{Introduction}

Language learning can benefit from learning strategies. This seems to be the most significant agreement among scholars in this subject; however, there are also controversies and criticisms. Reaching an agreed definition of strategies is one of the major challenges (Oxford, 1990; Oxford \& Cohen, 1992; Macaro, 2006; Di Carlo, 2017a). Furthermore, in many cases, the theoretical concept of learning strategy lacks precision or tends to be so global that it is complex to take it to the empirical field and can even affect the psychometric properties of the study (Dörnyei, 2005), therefore the importance of looking for solutions.

There are instruments used in research on learning strategies that were built upon similar, but not exactly definitions of strategies. All of these tools provide important information on learning strategies and apply different response modalities. For instance, the Learning and Study Strategies Inventory (LASSI) ${ }^{1}$ attempts to gather opinions with five response options that vary from not all typical of me to very much typical of me. Similarly, the Strategy Inventory for Language Learning (SILL) ${ }^{2}$ presents five options in terms of frequency, from never or almost never true of me to Always or almost always true of me. Along this line, the Cuestionario de Estrategias de Aprendizaje (Questionnaire of Learning Strategies) ${ }^{3}$ and the Cuestionario de Estrategias Cognitivas de Aprendizaje y Estudio (Questionnaire of Cognitive Learning and Study Strategies) ${ }^{4}$ have five response options ranging from never to always. On the other hand, in the Language Strategy Use Inventory ${ }^{5}$, the options are given considering an interest or acceptation degree, according to four options varying from $I$ use this strategy and like it to This strategy doesn't fit for me. Even though these Likert-type scales are summative as regards the scores obtained with respect to the strategy use, they are not strictly psychometric in terms of strategic competence. Let us analyze it from this perspective: the sum of the items can lead one to believe that the more frequent the use of strategies (higher score in the scale) is, the better developed the strategic competence is. This is not necessarily true because when referring to learning strategies their impact on achieving goals would be more important than the quantity or frequency. A strategically competent learner uses a strategy which is beneficial according to his/her personal features and the situation that comes up. Consequently, one learner can consider always using a strategy to be beneficial while another can consider that strategy not equally useful with the same frequency. Furthermore, there are no guarantees that an increase in the frequency with which a certain strategy is used will correlate with the best performance in learning. A clear example can be that of a learner who tries to learn a language by rote repetition of isolated and random words from a dictionary all the time. The frequency of this activity would give the top score, but what kind of development does it produce in learning? Therefore, we suppose that adding the scores of the different items in a frequency scale does not relate in a strictly linear manner to the underlying strategic property. This is also stated by Dörnyei (2003), who warns that not all the variations in Likert or Likert-type scales are summative in a psychometric sense. He mentions that the Oxford SILL built in 1989 can lead to a clear example of misinterpretation by believing that the main strategic skills of a person are reflected in a higher frequency of use (Dörnyei, 2003). In addition, he highlights that the most relevant aspect of a strategy is not the number of times it is used:

However, with regard to learning strategies this is not the case, since it is the quality rather than the quantity of the strategies a person utilizes that matters (Dörnyei, 2003, p. 39).

In this line, Fan (2003) conducted a research where he sought answer to the question whether or not there

\footnotetext{
1 See Weinstein, Schulte, and Hoy (1987).

2 See Oxford (1990).

3 See Beltrán Llera, Pérez Sánchez, and Ortega (2006).

4 See Rodríguez Fuentes (2009).

5 See Cohen, Oxford and Chi (2002).
} 
are any discrepancies between frequency of use and perceived usefulness of strategies. His study was the largest scale project ever conducted in Hong Kong concerning the English learning by 1,067 Cantonese speakers (40\% male and $60 \%$ female). For data collection he used a Vocabulary Test and the Vocabulary Learning Strategies Questionnaire. Results of one-way ANOVA and Bonferroni Multiple Comparison Test indicated significant discrepancies between the frequency of use and perceived usefulness of vocabulary learning strategies. These findings confirmed the author's earlier works (Johnson \& Fan, 1996; Fan, 1998).

Hence, the strategic aspect in learning is subjective; it is an internal assessment that depends on each person after performing a certain action to achieve an objective or a goal. Therefore, being $U$ the universe of possible actions, the learner chooses and uses a subset $A$ in order to attain goals and objectives of learning. In subset $A$ there will be elements which will result more useful than others in different contexts. I call these elements strategies and classify them as another subset $S$. Since every action in specific circumstances, it may be interesting to know when, where, how frequently, etc. it takes place. These questions, which include circumstantial aspects, are usually applied in L2 studies. Between 1985 and 1996 SILL was used to measure frequency of strategy use in studies involving approximately 10,000 language learners (Kaylani, 1996). Even later studies have been using SILL, for example, Griffiths (2003), Rahimi, Riazi, and Saif (2008), Kazamia (2016), Kambakis (2016), Tezcan and Deneme (2016), to name but a few. Although the data obtained by them are of interest, they leave aside questions relating the impact or usefulness, which is probably the most important underlying trait. In fact, in the empirical field, as reflected from the aforementioned instruments, the frequency of use acquires almost exclusivity.

In this study, language learning strategies are considered according to Di Carlo (2017a) as those actions defined by their usefulness, which include the two key attributes that underlie the concept of strategy: efficacy $(\varepsilon)$ is "the degree to which goals and objectives are positively achieved" (Di Carlo, 2017a, p. 47), and efficiency ( $\eta$ ) which refers to the amount of resources which are required for any cognitive activity (Di Carlo, 2017a). Probably, one of the most extended ways to classify language learning strategies relies on their function. Oxford (1990) and O'Malley and Chamot (1990) organized strategies in functional groups, and cognitive strategies were present in both classifications. The interest in this study is put into cognitive strategies, since they are key to optimize assimilation, internalization, construction, consolidation and transference of knowledge and language skills. They are represented by cognitive pillars that underlie the coding, storage and recovery of information.

In this work cognitive language learning strategies (CLLS) are classified according to their predominant function in five categories defined by Di Carlo (2017b): classification, preparation, association, elaboration and transfer-practice. This author's taxonomy is based on the interdisciplinary contributions of cognitive psychology, neuroscience and linguistics to give a wider and more complete perspective on the phenomenon of L2 learning. It is beyond the scope of this work and cannot be detailed here due to limits in extension, but further details are given in his article. The categories are described by Di Carlo (2017b) as follows. Classification strategies help to discriminate, select and classify or categorize information so that it is much simpler, quicker and more organized to carrying out subsequent structuring and representations of knowledge. The function of Preparation strategies is to establish representational, intentional and non-randomized relations between the new signs and the psychological meanings already established in the idiosyncratic structure. They also help to develop initial auditory, motor, visual and articulatory skills through simple procedures. The function of Association strategies is to create associations in different and more particular or more global dimensions, whether they are new or known. Moreover, they contribute to establishing relations, links and comparisons between new content and previous schemata. The function of Elaboration strategies is to structure, build and deepen the conceptual units while new information is obtained. They help to elaborate or re-elaborate information at a complex semantic level and integrate the different parts of the information. Finally, Transfer-practice strategies allow the learner to expand and transfer the application of knowledge and skills to other specific and general contexts. They help to promote the development of microskills and macroskills as well as to consolidate associative links.

In this study, the following hypotheses were posited: (a) L2 adult learners use different types of cognitive 
language learning strategies, (b) the perceived usefulness of specific strategies varies from learner to learner, and (c) there are strategies that are more useful according to most SL2 adult learners. Hence, the research questions were:

$>$ What type of cognitive language learning strategies do adult students of Spanish as a second or foreign language (SL2) use?

$>\quad$ Which cognitive strategies are more useful according to most SL2 adult learners?

The objectives were to identify and describe the types of cognitive language learning strategies used by SL2 adult students.

\section{Method}

\subsection{Participants and contexts}

The study population included adult learners of Spanish as second or foreign language from Europe, United States, Canada, Brazil, Australia and New Zealand. The non-probability sampling - accidental, convenience or opportunity sampling, according to Dörnyei (2003) — was formed by 665 valid participants $(N=665)$, mostly college students (75\%) from Europe, Brazil and English-speaking countries who were learning Spanish as an optional foreign language or academic-professional purposes, such as becoming translators, bachelors in Hispanic Philology, and teachers of Spanish. There were local students from 54 universities in 18 countries: Germany, Australia, Belgium, Belarus, Brazil, Canada, Denmark, United Sates, Finland, France, Greece, Hungary, Italy, New Zealand, Portugal, Czech Republic, Sweden and Switzerland. Included within this context of Spanish as a foreign language, there were also adult participants from non-university educational institutions of Spanish in France (Institution A) and Belgium (Institution B).

In the context of Spanish as a second language, the following were part of the sample: (a) foreign students and teachers participating in exchange programs at Institution C (Colombia), (b) French-speaking immigrants in Argentina, (c) undergraduate and graduate from the United States, Brazil and European countries studying at Institution D (Spain) and (d) foreign learners of Spanish at Institution E (Spain).

In total, 149 men and 516 women participated with the following age distribution: 17-20 years old: $30 \%$; 21-25 years old: $46 \%$; $26-39$ years old: $16 \%$; 40 years old or older: $8 \%$. The mother tongues of the subjects were: French (21\%), English (15\%), German (15\%), Italian (17\%), Greek (8\%), Dutch (8\%) and 25 additional languages which reached 16 percent. In the sample, every competence level in L2, from the very beginner to the very advanced, was represented.

\subsection{Measures and Procedure}

In this non-experimental descriptive study, data collection was carried out through the Scale for the Identification of Cognitive Language Learning Strategies (SICoLLS). The survey was built upon theoretical principles and empirical data obtained from dozens of interviewed learners of Spanish from Europe, Brazil and English-speaking countries in different situations and contexts both, as a foreign and as a second language. Details about construction process, psychometric properties, and pilot testing exceed the present article. This is an instrument created to identify and assess cognitive language learning strategies in students of Spanish as a second or foreign language. Technically, it is a self-completion multi-scale survey, which contains five categories or subscales. The total scale consists of 80 items (affirmative statements) that represent potentially strategic actions. For each item, participants may choose graduated responses through a self-positioning scoring scale between 1 and 100. It measures the personal perception (self-perception) of the level of usefulness of actions, procedures and mental operations adopted to optimize the assimilation, internalization, construction, consolidation and transference of knowledge and language skills. In other words, it measures the usefulness 
perceived by the L2 learner about those potentially strategic actions in terms of efficacy $(\varepsilon)$ and efficiency $(\eta)$ to achieve goals and objectives of linguistic learning, face difficulties, optimize/exploit strengths and overcome weaknesses in this process. Assessment can happen at three levels: global (if the total score of the inventory is considered), category (if the score by category is considered) and individual (if a certain item is considered).

One of the most challenging stages of this work was the operationalization of strategies defined by the two properties: efficacy and efficiency. The effective trait in learning is subjective; it is an assessment that depends on each person after performing a certain action to achieve an objective or a goal. A huge experimental study should be carried out to confirm with absolute certainty whether an activity is strategic or not in a determined context and with a defined objective. Said study would involve performing countless tasks from a universe of possibilities under the same conditions, and then comparing these results to find out which the most effective activities were. This undertaking is beyond any rational possibility of execution, given our mortal nature and the resource limitation for such a purpose, hence, the reason to resort to the metacognition of individuals and the perceived usefulness. The concept of efficiency is even more complex to be operationalized. The quantification of the used resources (time, cognitive effort, materials, etc.) in a determined learning action proves extremely difficult, if not, impossible to assess empirically. Still, it was obligatory to include the concept of efficiency; otherwise, the main objective could not be achieved: the identification of strategies, in the strict conceptual sense adopted in this work. The most viable option was to include the concept of efficiency in the construction of the instrument, by referring to the minimum of resources as a constant, and trusting in the metacognition and in the previous experience of the respondent on the performed activities. Perhaps it is not the most precise option, but it was accepted as the most feasible proposal.

Since learning strategies are conscious or potentially conscious mental actions, it is highly probable that the subjects are aware of the intention of doing a certain activity, that they know the tasks to be performed and their requirements, and above all, that they may evaluate the process and adapt it, including the record of the perception of the resulting usefulness. That is why, in the instrument used, we included questions directed to that body of reflexive, verbalizable and potentially conscious metaknowledge. However, supporting the results based exclusively on metacognition imposes the limitation of lacking absolute certainty about the precision in the appreciation and the evaluative capacity of the respondent about their activities. Additionally, there may be interpretation mistakes, distractions, and conditioning elements, internal as well as external to the subject, which can lead them to answer in a way that is not exactly what it actually should be or what they wanted it to be. Despite that, the responses that were not exactly real are very close to being real, and since this was a large sample, it is possible to identify trends and estimations from those approximations, even when there were deviations, analogous to what happens with the trend line drawn in a scatter plot.

My assessment tool (SICoLLS) recognizes the possibility that the respondent may leave items unanswered in order to avoid pseudo-opinions that could appear in cases where the learners ignore or do not use any type of action mentioned in the scale. The instrument was administered in a digital manner to save resources, grant access to a greater number of subjects, facilitate completion, and speed up data collection and its subsequent processing; moreover, the application of a self-completion modality in the scale would be more difficult and inaccurate if done without computer support.

In order for subjects to be able to read and answer in their mother tongue (or in another language which they would know better than Spanish), I decided to translate the instrument from Spanish into English, French, Portuguese and German. In this way, I followed the conventional line in this type of study (O'Malley \& Chamot, 1990) and avoided possible mistakes in interpretation, especially in those subjects with a less developed level of reading comprehension in Spanish. I defined a translation protocol which referred to the suggestions made by the World Health Organization (2010), Harkness and Schoua-Glusberg (1998), and Rahman, Iqbal, Waheed, and Hussain (2003). The translation and adaptation process of the chosen instrument aimed to create versions which would be conceptually equivalent in each target language and culture, that is, emphasis was placed in interculturality and in the conceptual aspect, instead of in the literal equivalence. It consisted of four stages: (a) 
direct translation, (b) back translation, (c) cognitive interviews, (d) discussion and adjustments. The final version of SICoLLS (accessible in five languages) is available at http://bit.ly/296JWWM (web-based material). Professors and heads from different institutions were requested to cooperate. Those who accepted facilitated the survey to their students. Participation was voluntary and anonymous. It was not a part of any course, and there was no compensation of any kind. The required average time to complete the survey was 15 minutes.

The reliability of the instrument was determined by measuring the internal consistency, for which two techniques were applied: calculating both Cronbach's alpha and item-total correlations with the statistical package IBM SPSS v.22. Cronbach's alpha coefficients for each scale were acceptable since they exceeded the value of 0.7 in every category: classification $(\alpha=0.78)$, readiness $(\alpha=0.87)$, association $(\alpha=0.87)$, elaboration ( $\alpha=0.86)$, practice and transference $(\alpha=0.82)$, total scale $(\alpha=0.95)$. Item-total correlations were also calculated and the only items that showed correlation values lower than 0.25 in their scales were: $12,13,20,41,45,67,72$, 75,76 and 80 . However, there was no need to discard items, since their elimination did not produce a significant increase in Cronbach's alpha.

The validity of the construct was previously obtained through the satisfactory evaluation of four specialists in linguistics, each with more than 20 years in teaching and research, who made comments regarding some items, hence revisions were made. The later version was also presented to six learners of Spanish with an intermediate to advanced level in reading comprehension in Spanish (two English speakers, two Portuguese speakers and two German speakers) for them to indicate doubts, explain their interpretation and make comments. With their contributions, a pilot test with 70 students was administered and the results were deemed to satisfactory so the SICoLLS was then administered to the final sample.

\section{Results}

To answer the research questions, a descriptive statistical analysis of the total scale and of each category subscale with their corresponding items was carried out. Calculations were performed using statistical software IBM SPSS v.22 and Microsoft Excel spreadsheet software.

\subsection{Descriptive Statistics for Classification Scale}

In this paper, the missing values represent the unawareness or absence of the activity referred to in the corresponding item of the instrument. Around 459 subjects completed every item of the Classification scale without leaving blanks while 206 subjects left unanswered at least one of the 14 items. Only $6 \%$ of the entries were incomplete (591 missing values, unassigned scores), implying that $94 \%$ of the activities referred to by the items of the scale were known or used by the sample ( 8,719 complete data, assigned scores).

Table A.1 (see Appendix) provides the details of the descriptives for this scale. Items 01, 03, 04, 05, 06 and 07 presented few missing values and high values of arithmetic mean (score equal or higher than 70), with item 01 on top of the scale, which in turn was the most representative, since it had the lowest dispersion of values around the arithmetic mean (lowest value of standard deviation).

In items 08 to 14, a decrease in the average score, an increase in dispersions and a significant increase in the number of missing values were observed. Item 11 had the highest percentage of missing values in the scale (18\%) and the greatest deviation, but the lowest score of average usefulness. However, there were opposing valuations in this item since 52 subjects gave it the highest usefulness score (contrary to the majority).

\subsection{Descriptive Statistics for Preparation Scale}

Around 403 subjects completed every item of the Preparation scale without leaving blanks while 262 subjects left unanswered at least one of the 16 items. Twelve percent of the entries were incomplete $(1,322$ missing values, unassigned scores), implying that the activities referred to by the items of the scale were known 
or used by the $88 \%$ of the sample ( 9,318 complete data, assigned scores).

Table A.2 (see Appendix) provides the details of the descriptives for this scale. Items 15, 16 and 19 showed the lowest missing values, together with high mean values (score equal or higher than 70). In items 24 and 25, high missing values together with the lowest scores of the scale, 28 and 23 respectively, are shown. However, even with the lowest values of score due to a majority that evaluated them as useless, item 24 as well as 25 were considered useful by some subjects: for item 25 , there were 61 subjects who assigned a score of 70 or higher, which represented $12 \%$ of the total valid responses $(n=461)$, while for item 24 there were 66 subjects who assigned a score of 70 or higher, which represented $13 \%$ of the total valid responses $(n=511)$. Histograms of items 15, 18, 19 and 30 showed very similar frequency distributions and an important majority of subjects who assigned the highest score of usefulness. In the histograms of items 22, 23 and 29, there were similar frequency distributions and a remarkable divergence with regard to the perceived usefulness because scores were very heterogeneous.

\subsection{Descriptive Statistics for Association Scale}

Around 406 subjects completed every item of the Association scale without leaving blanks while 259 subjects left unanswered at least one of the 18 items. Thirteen percent of the entries were incomplete $(1,582$ missing values), implying that the activities referred to by the items of the association scale were known or used by $87 \%$ of the sample $(10,388$ complete data).

Table A.3 (see Appendix) provides details of the descriptives for this scale. Items 41,43 and 45 presented the lowest missing values together with high mean values $(M \geq 70)$, with item 41 at the top of the scale, which had the highest and most representative value, since it had the lowest dispersion of values around the arithmetic mean (lowest value of standard deviation).

Items 35,39 and 48 had the lowest score values and the highest number of missing values. Items 41, 43 and 45 stood out not only because of their high values but mainly because of their very low percentages of low scores and accumulations in the highest score (100). This suggests that the usefulness of the activities they referred to could be relatively independent of other variables that were present in the selected heterogeneous sample. The opposite occurred in items $34,36,37,44,46$ and 47 , which presented very varied valuation scores, mainly item 44 , according to the analysis of histograms.

\subsection{Descriptive Statistics for Elaboration Scale}

Around 412 subjects completed every item of the Elaboration scale without leaving blanks while 253 subjects left unanswered at least one of the 14 items. Thirteen percent of the entries were incomplete $(1,246$ missing values), implying that the activities referred to by the items of the elaboration scale were known or used by $87 \%$ of the sample ( 8,064 assigned scores). Table A.4 (see Appendix) provides details of the descriptives for this scale. Item 56 showed the lowest number of missing values together with a high mean value $(M \geq 70)$. At the top of the scale, this item had the highest and most representative value, since it had the lowest dispersion of values as regards the arithmetic mean (lowest value of standard deviation). On the other hand, item 51 led the lowest values (and the highest number of missing values), followed by items 54 and 55. Despite being an item with a lower score, $25 \%$ of the respondents assigned a usefulness score of 70 or higher.

The histograms of items 50,52, 54, 55 and 60 (associated with reflection, deduction and synthesis) presented broad differences with respect to perceived usefulness, since scores were very diverse: there were subjects who assigned null usefulness and another similar number of individuals who assigned maximum or medium levels of usefulness. Furthermore, frequency distributions of items 56, 59, 61 and 62 showed considerable similarities. In contrast with what it was already mentioned, items 56 and 62 were very homogeneous regarding their perceptions of usefulness, since the activities described in these items rated with high scores by the vast majority. 


\subsection{Descriptive Statistics for Transfer and Practice Scale}

Around 369 subjects completed every item of the Transfer-Practice scale without leaving blanks while 296 subjects left unanswered at least one of the 18 items. Fourteen percent of the entries were incomplete $(1,659$ missing values), which means that the described activities in the items of the scale are known or used by $86 \%$ of the sample (10,311 assigned scores).

Table A.5 (see Appendix) provides details of the descriptives for this scale. Items 66, 74 and 79 presented the lowest missing values, together with high mean values (equal or higher score than 70), being item 79 at the top of the scale with the highest value. On the contrary, item 76 had the lowest values (and the greater number of missing values) followed by items 65,75 and 80 . Although it was the item with the lowest score, for $19 \%$ of the survey respondents, this item had a usefulness of 70 or higher.

The histograms of items 65, 68, 69, 70, 71 and 72 showed broad differences in terms of perceived usefulness, since there were subjects who assigned null usefulness and another similar number of subjects who assigned maximum or medium levels of usefulness. Furthermore, frequency distributions of items 66, 74 and 79 showed considerable similarities, with a great number of participants that rated them with the highest scores.

\subsection{Descriptive Statistics for Total Scale}

Around 301 subjects completed every item of the scale without leaving blanks while 364 subjects left unanswered at least one of the 80 items. Twelve percent of the entries were incomplete (6,400 missing values), which means that the activities described in the items of the total scale are known or used by $88 \%$ of the sample (46,800 complete values). In order to determine the nature of the missing values, an estimation analysis of the statistical data through an expectation-maximization algorithm (EM) was performed on the 80 variables of the scale. Furthermore, Roderick J. A. Little's chi-square statistic for testing was calculated to determine whether the missing data are missing completely at random (MCAR), with the following result: $\chi^{2}=20732, \mathrm{DF}=21182, p$ $=.986$. As $p>0.05$, null hypothesis is accepted and data are missing completely at random (MCAR). This means that the characteristics of the subjects with information are the same as those of the subjects without information. In other words, the chance that a subject presents a missing value in a variable does not depend on the value of other variables of the scale or on the values of that variable with missing values.

In order to identify which cognitive language learning strategies (CLLS) were the most useful, we computed the percentages of respondents who assessed the usefulness $\boldsymbol{v}$ of every single item of the 80 items of the scale with a score higher or equal to 70. Table 1 shows the detailed data, where $Q$ is the number of participants who assessed the item with 70 or more $(v \geq 70)$ and $Q(\%)$ is the same quantity expressed in per cent of the item's total valid values. The list was made up of 30 items representing the most useful potential strategies to the most people with their corresponding percentages. I call these items majority strategies since they can facilitate the achievement of $70 \%$ or more of the objectives in an efficient way for the $50 \%$ (or more) of respondents. It is interesting to note that the five categories were present in the list in similar proportions: Classification ( 7 items, 23\%), Preparation (6 items, 20\%), Association (5 items, 17\%), Elaboration (5 items, 17\%), and Transfer-practice (7 items, 23\%).

Subject 347 in the data base, a Dutch-speaking 54-year-old woman, was the case with the minimum total score assigned in the scale (584 over a maximum of 8000). Even in this atypical case, it can be observed that a usefulness score of 100 was given to strategy $01 \mathrm{CL}$, and 50 to items 31, 46 and 66. This indicates that at least one individual out of all the subjects $(N=665)$ used a cognitive language learning strategy. 
Assessing cognitive learning strategies: A global study of Spanish learners

Table 1

Summary of Cognitive Majority Strategies

\begin{tabular}{|c|c|c|c|}
\hline Item & Strategy & Q & $\mathrm{Q}(\%)$ \\
\hline & Classification & & \\
\hline 01 & I take notes of the explanations from those I consider experts in Spanish. & 509 & $78 \%$ \\
\hline 02 & I write what I don't understand in my notebook. & 367 & $57 \%$ \\
\hline 03 & I mark what I don't understand in texts. & 421 & $65 \%$ \\
\hline 04 & I mark what I consider important in texts. & 484 & $74 \%$ \\
\hline 05 & When I want an example, I look for it in a book, web site, etc. & 397 & $61 \%$ \\
\hline 06 & When I don't understand something, I ask someone to explain it to me. & 422 & $64 \%$ \\
\hline 07 & $\begin{array}{l}\text { When I am unsure, I consult learning materials. } \\
\text { Preparation }\end{array}$ & 444 & $67 \%$ \\
\hline 15 & I write new or difficult words or phrases. & 407 & $63 \%$ \\
\hline 16 & I read new or difficult words or phrases several times. & 381 & $59 \%$ \\
\hline 18 & I say new or difficult words or phrases aloud several times. & 329 & $52 \%$ \\
\hline 19 & I mentally repeat new or difficult words or phrases. & 393 & $62 \%$ \\
\hline 21 & I sing parts of songs. & 335 & $54 \%$ \\
\hline 30 & $\begin{array}{l}\text { I read to familiarize myself with grammatical structures and vocabulary. } \\
\text { Association }\end{array}$ & 374 & $59 \%$ \\
\hline 33 & I link what I learn to a context or situation. & 324 & $53 \%$ \\
\hline 41 & I look for the definition of words I do not know. & 466 & $72 \%$ \\
\hline 42 & In order not to use the same words, I learn others that have the same meaning. & 312 & $50 \%$ \\
\hline 43 & When I learn a Spanish word, I think about words in my language that have equivalent & 428 & $67 \%$ \\
\hline 45 & $\begin{array}{l}\text { I write new Spanish words along with their translation in my language. } \\
\text { Elaboration }\end{array}$ & 426 & $68 \%$ \\
\hline 49 & I deduce the meaning of words from their use in different situations. & 357 & $57 \%$ \\
\hline 56 & I try to get the general idea of what I read. & 454 & $72 \%$ \\
\hline 59 & I write explanations in my own words. & 322 & $54 \%$ \\
\hline 61 & I create my own material for studying and revising. & 335 & $56 \%$ \\
\hline 62 & $\begin{array}{l}\text { I pay attention to everything that happens in conversations carried out by other people. } \\
\text { Transfer-practice }\end{array}$ & 333 & $53 \%$ \\
\hline 64 & I apply what I learn in real communication situations. & 352 & $58 \%$ \\
\hline 66 & I try to imitate people I consider to be experts & 387 & $63 \%$ \\
\hline 67 & I write down the conjugations of the most important or difficult verbs. & 331 & $56 \%$ \\
\hline 73 & I participate in face-to-face conversations. & 294 & $52 \%$ \\
\hline 74 & I ask someone who knows Spanish to correct me. & 392 & $64 \%$ \\
\hline 78 & I watch films with audio in Spanish and without subtitles. & 305 & $53 \%$ \\
\hline 79 & I listen to music in Spanish. & 441 & $69 \%$ \\
\hline
\end{tabular}

\section{Discussion}

\subsection{Findings and Implications}

It is true that the sample was so varied, in fact we could not find any precedent study including such a wide range of participants and contexts regarding Spanish learning in a single pool. The very large and diverse data set provided a broader scope and allowed us to include a lot of underlying variables. For example, university and non-university Spanish learners, graduates and undergraduates, learners taking Spanish as an elective or as a requirement for a specific professional goal, students taking Spanish as a foreign language (e.g., those taking Spanish in the U.S.) and as a second language (e.g., Colombia and Spain), etc. These variables, such as different linguistic background, different proficiency level, different learning context, and many more, are extremely important, and we could assume that they might affect language learning strategy selection and assessment. As expected, results showed that there were strategies that showed significant variability in perceived usefulness, however, there were also items with very little variation in scores, which could be unaffected by the large set of factors aforementioned. Finding this important outcome was only possible thanks to the varied mix in the sample. 
Three patterns of variation were observed according to the scores. First, accumulations of majority positive ratings, for example, items $01,15,41,43,45,66$ and 79. The activities described in these items might be considered as more stable and independent from other factors. The same considerations are valid for those items that showed accumulations of minimum ratings, for example, items 24, 25, 39, 48 and 76. On the other hand, scores homogeneously distributed among the possibilities of the scale were observed in items $09,22,37,44,46$, $47,65,68$, for example. These items could be more easily influenced by different factors that should be further determined. Figure 1 illustrates the three patterns in items 25, 44, and 41. We could observe that there were always percentages of respondents with high scores for every item $(v \geq 70)$, even in lowest rated items. Figure 1 also shows the framed rectangles that stand for the numbers of scores of usefulness $v$ higher or equal to 70 for the example items 25,44 , and 41 .

The results show that the five categories (Classification, Preparation, Association, Elaboration, and Transfer-Practice) are proportionally distributed among the majority strategies, thus, the five categories are equally useful and important in learning. What do these results mean? This suggests that the comprehensive development of the communicative competence is achieved by the contribution of different actions, whose predominant functions are aimed to promote the growth of different areas, both on the cognitive level and on the neuronal level.

The majority strategies we found have different predominant functions, typical of their corresponding categories. Each of them could be associated with different pedagogical approaches; for example, the activities of repetition fit into the audio-lingual approach, while elaboration activities are more typical of the communicative approach. What does this mean for classroom instruction? It means different actions can be included in different pedagogical approaches at classroom; for this reason, it turns out that there is no single method that is equally useful for developing every aspect of the communicative competence or for all learners, in all the circumstances. Hence, instructors should consider implementing a wide variety of tasks with the students, including those described in each of the categories.
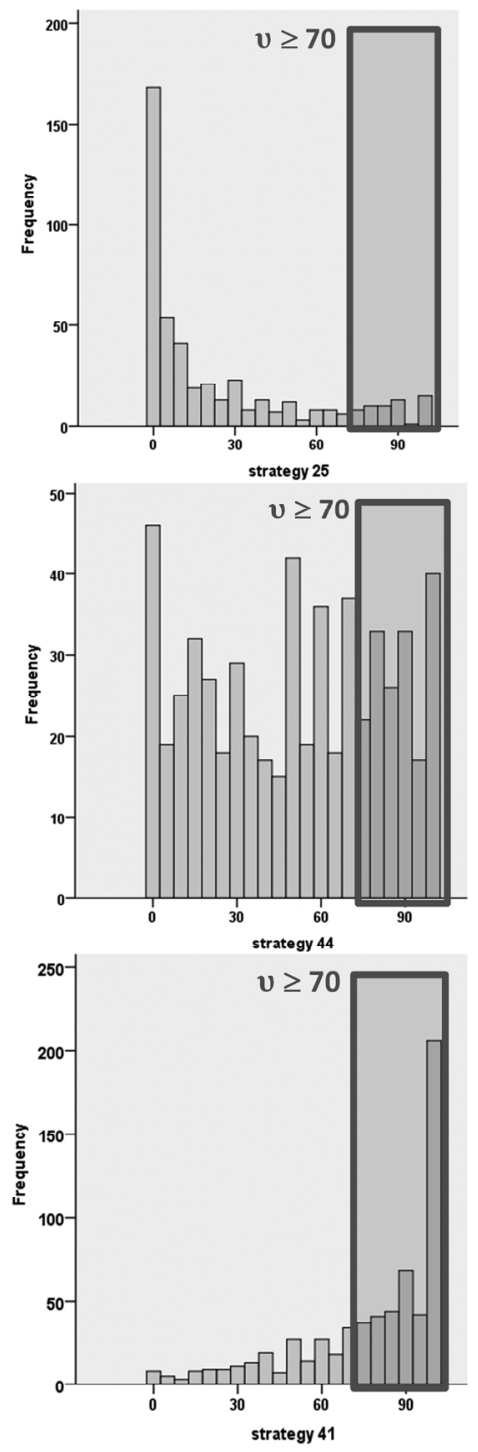

Figure 1. Examples of the three patterns of variation

Identifying the 30 majority strategies has important implications for instruction. All of these strategies showed to be highly scored by the $50 \%$ (or more) of respondents, however, the assessment on the strategies within this list varied regarding the number of participants (Q), as showed in Table 1. Based on these results, I recommend instructors or learners to emphasize the following strategies in class activities or assignments (Table 2). Different degrees of recommendation were assigned to strategies regarding their Q: high ( $78 \% \geq \mathrm{Q} \geq 65 \%)$, moderate $(64 \% \geq \mathrm{Q} \geq 57 \%)$, and medium $(56 \% \geq \mathrm{Q} \geq 50 \%)$. The highly recommended strategies were also more stable and unaffected to variation in scores across participants; hence, they are likely to be used in any context by any learner with effective outcomes. 
On the contrary, I also suggest the following five strategies to de-emphasize, since they had lowest scores and showed accumulations of minimum ratings: Drawing the meanings of new words; saying rhymes or tongue twisters; making jokes with new words; inventing stories using words that I want to learn; watching films with audio in my language and subtitles in Spanish. Keep in mind that we are never going to know with certainty the usefulness of a certain strategy; hence, I encourage learners to try as many activities as they can. This information could serve as a reference and would be of great interest to teachers, researchers and learners of Spanish language, who could take advantage from knowing the most effective strategies used and assessed by other hundreds of subjects. Furthermore, more similar studies would help to obtain statistical trends for experience from thousands, or even millions of learners, which would contribute to find more robust and priceless results.

The confirmation of the formulated hypothesis about the existence of different degrees of perceived usefulness of potential strategies has pedagogical and methodological implications that deserve further discussion. First, there is a trend at present to adopt the communicative approach in the materials (or at least, this is what it is stated in the presentations of manuals) and in the institutional programs of education of Spanish. In this approach, according to the underlying pedagogic perspective, the activities related to repetition are not implemented, for example. Therefore, the potential effects derived from this type of action (such as adapting the perceptual and effector components to operate with the new linguistic signs, and developing initial auditory, motor, visual and articulatory skills) would not take place. This situation deserves, at least, consideration on the part of the teacher, since, according to the results, this kind of activities were among the most useful for the learners.

On the other hand, let us think of how much has been debated and investigated on the question whether the induction or the deduction of grammatical rules is better, with supporters at both ends. It was possible to state that strategy 50 (I deduce grammatical rules and I make generalizations) turned out to be one of the most heterogeneous variables regarding its perceived usefulness, which suggests that the superiority of deduction over induction (or vice versa) cannot be confirmed.

\section{Table 2}

\section{Recommended Strategies}

\begin{tabular}{ll}
\hline & \multicolumn{1}{c}{ Strategy } \\
\hline Taking notes of the explanations from those I consider experts in Spanish. & \\
Marking what I consider important in texts. & high \\
Looking for the definition of words I do not know. & \\
Trying to get the general idea of what I read. & \\
Listening to music in Spanish. & \\
Writing new Spanish words along with their translation in my language. & \\
Consulting learning materials when I am unsure. \\
Thinking about words in my language that have equivalent meanings when I learn \\
a Spanish word. \\
Marking what I don't understand in texts. \\
\hline Asking someone to explain it to me when I don't understand something. \\
Asking someone who knows Spanish to correct me. \\
Writing new or difficult words or phrases. \\
Trying to imitate people I consider to be experts \\
Repeat mentally new or difficult words or phrases. \\
Looking for the examples I want in a book, web site, etc. \\
Reading new or difficult words or phrases several times. \\
Reading to familiarize myself with grammatical structures and vocabulary. \\
Applying what I learn in real communication situations. \\
Writing what I don't understand in my notebook. \\
Deducing the meaning of words from their use in different situations.
\end{tabular}


Table 2 ... continued

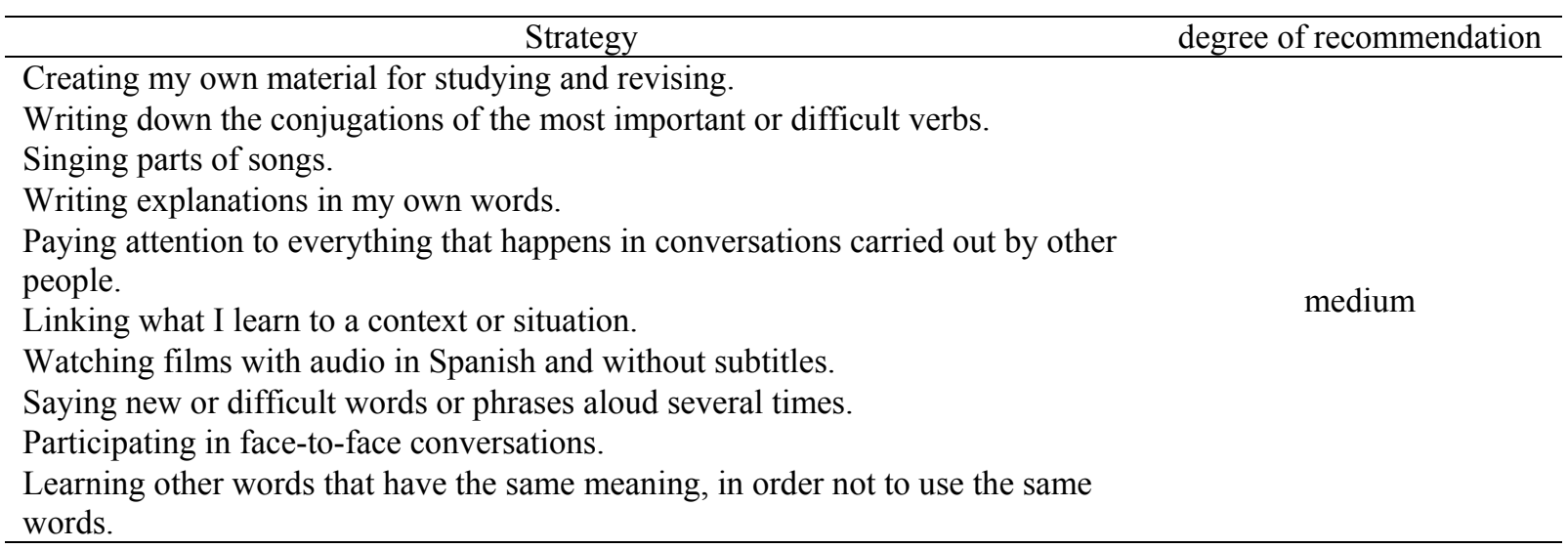

These findings invite us to conceive learning as a process characterized by subjectivity and individualization, but which can be built with the contributions derived from the statements and the experience of hundreds of learners. The probabilistic trends in the empirical field reveal common cognitive processes in human beings, which - complemented with theoretical advances - help to establish parameters, categories, criteria, and indicate a need to take into account a wider series of options, to present new proposals and to question approaches, both traditional and new, used in scientific and pedagogical fields.

\subsection{Statement of Support for Hypotheses and Objectives}

Statistical analyses performed on each of the items (arithmetic means, standard deviations and histograms) confirm that the assigned usefulness values are heterogeneous and that this variation was present in every single item of the scale. This means that there was no item with an absolute accumulation at just one value. Hence, three major patterns of variation were observed: (a) accumulations of majority positive ratings, (b) values homogeneously distributed among the possibilities of the scale, and (c) accumulations of minimum ratings. These results support the second hypothesis formulated and they confirm what had been anticipated in the theory about the diversity of usefulness across adult learners. Furthermore, due to these analyses it could be determined which strategies were majority strategies were and what type of strategies they were. Thirty majority strategies facilitate the achievement of $70 \%$ of the objectives or higher in an efficient way for $50 \%$ of the respondents or more were identified and described quantitatively. This finding supports the third hypothesis formulated and the second question is therefore answered.

Additionally, the results show that there was neither an item without a usefulness score higher than 70 (at least once) nor a subject who did not select at least one strategy. Looking at the variation patterns in histograms, we could observe that there were always percentages of respondents with high scores $(v \geq 70)$, even in lowest rated items.

There were majority strategies in every category and this shows that strategies of different types and with different functions are used. Finally, the complete entries in the total scale constitute $88 \%$, which means that the great majority of the activities described in the items of the scale are used by the subjects and that the instrument presents a representative repertoire of the learning activities used by them. These results clearly support the first hypothesis formulated. In short, the types of CLLS used by students of SL2 were identified and quantitatively described and it was possible to determine which of them are perceived as the most useful by most of them, answering the research questions and successfully achieving the corresponding objectives.

\subsection{Generalizability}

The idea of generalizing these results to the 21 million learners of Spanish around the world (Instituto Cervantes, 2016) is a bit risky, due to the great variety of contexts and cultural realities. In this study, efforts have 
been made to include a great number of participants with different characteristics and from different learning environments in order to perform quantitative analyses that, by definition, tend to look for the generalization of results. The instrument of data collection was designed from samples of learners of Spanish in different contexts and situations, from Europe, Brazil and English-speaking countries. The main sample underpinning this work was coincidental with this criterion of selection. In our opinion, replicating this study or implementing the instrument in other contexts, with cultural practices and linguistic systems very different from the western standards shared by the places included in this study, would help us to have a more comprehensive view based on more extensive results and, therefore, more generalizable to the population of learners of SL2. Though there would not be major issues in this process, we suggest performing a previous diagnosis in these dissimilar environments in order to identify possible difficulties caused by differences of diverse nature. Likewise, since the present study is the first one of this specific type, to replicate it in contexts similar to those of the genesis is also advisable in order to estimate similarities or differences that would contribute to a more comprehensive vision of the generalization.

\subsection{Suggestions for Future Studies}

In this paper, the different categories have been defined to classify the CLLS from a theoretical perspective; nevertheless, how they relate to each other in the empirical level is still unknown. It would be very interesting to complement the results with a study aiming at discovering dimensions of common variability in the usefulness of potential CLLS, as well as to identify and describe the associations among them. Thus, if a certain strategy turns out to be useful, this would allow us to become aware of what the other strategies associated with it are and that might also be of the same usefulness.

Additionally, it has to be determined whether or not there are correlations between the usefulness of the CLLS and other variables, such as gender, proficiency level, mother tongue, and motivation, following a line of research similar to those in the studies carried out by Oxford and Nyikos (1989), Griffiths (2003), Rahimi, Riazi, and Saif (2008), Platsidou and Sipitanou (2014), Kazamia (2016), Gavriilidou and Petrogiannis (2016), Kambakis (2016), Tezcan and Deneme (2016) which examined the variables affecting the choice of frequency use in language learning strategies. Some of these factors have been considered in the collection of the data for our study, but are yet to be explored, so I invite researchers worldwide to join and analyze together underlying associated factors. Much remains to be explored regarding learning a L2, the strategies used and what factors could be correlated with it in order to be able to understand and intervene in the optimization of language acquisition. Lastly, this study was designed for the learning of Spanish, though it could be adapted for learners of other languages by comparing the results, so that it could be determined what differences or similarities exist among the strategies used by the different groups.

\section{Conclusions}

In short, what is new about the study and the most important findings are outlined below. This study was the first in bringing the concept of language learning strategy, defined in terms of efficacy and efficiency, to the empirical field. Since it is not possible to conduct such a huge number of experimental valuations to assess all the strategies, we turned exclusively to the metacognition of subjects about their learning experience and the perceived usefulness. For that purpose, a survey online tool was created to collect data.

This study was the largest scale project ever conducted concerning the Spanish learning by 665 adult subjects worldwide in such different contexts. Despite the large variety included in the sample, we could identify the strategies with very little variation in perceived usefulness. This suggests these strategies could be unaffected by the large set of underlying factors, such as gender, proficiency level, and mother tongue. On the other hand, strategies that showed significant variability in scores were also identified, and they might be more easily influenced by different factors that should be further determined. These results also evidence that perceived usefulness of strategies varies across learners in different degrees. 
The results showed which strategies can facilitate the achievement of the objectives in an efficient way for most of respondents. These 30 strategies are proportionally distributed in the five categories, so the comprehensive development of the communicative competence is achieved by the contribution of different actions with predominant functions/impacts in learning, both on the cognitive level and on the neuronal level. Majority strategies are recommended for learners because of the little variability in usefulness scores regarding possible affecting factors. On the other hand, minority strategies were identified and are not recommended, since they had lowest scores in perceived usefulness and showed accumulations of minimum ratings. However, the only way to knowing with certainty the usefulness of a certain strategy is using it and assessing it, so I encourage instructors and learners to increase the pool of available activities as much as they can.

It is too soon to evaluate the impacts of this study and it is necessary to continue working to get a more complete comprehension of the use and other aspects related to the cognitive language learning strategies. Nevertheless, the contributions of the results might constitute foundations of future potential studies and theoretical guidelines for teachers of Spanish.

\section{References}

Beltrán, J. A., Pérez, L. F., \& Ortega, M. I. (2006). Questionnaire on learning strategies [In Spanish]. Madrid: TEA Ediciones.

Chamot, A. U. (2004). Issues in language learning strategy research and teaching. Electronic journal of foreign language teaching, 1(1), 14-26.

Cohen, A. D., Oxford, R. L. \& Chi, J. C. (2002). Language Strategy Use Survey. In A. D. Cohen \& S. J. Weaver (Eds.), Styles and strategies-based instruction: A teachers'guide (pp. 68-74). Minneapolis: Center for advanced research on language acquisition, University of Minnesota.

Di Carlo, S. (2017a). A different perspective to define language learning strategies. International Journal of Research Studies in Language Learning, 6(4), 43-51. https://doi.org/10.5861/ijrsll.2016.1594

Di Carlo, S. (2017b). Understanding Cognitive Language Learning Strategies. International Journal of Applied Linguistics and English Literature, 6(2), 114-126. https://doi.org/10.7575/aiac.ijalel.v.6n.2p.114

Dörnyei, Z. (2003). Questionnaires in second language research: Construction, administration, and processing. New Jersey: Lawrence Erlbaum Associates.

Dörnyei, Z. (2005). The Psychology of the language learner. Individual differences in second language acquisition. London: Lawrence Erlbaum Associates.

Fan, M. Y. (1998). An investigation into the problem of encoding technical vocabulary. Asia-Pacific Journal of Teacher Education and Development, 1(1), 83-92.

Fan, M. Y. (2003). Frequency of use, perceived usefulness, and actual usefulness of second language vocabulary strategies: A study of Hong Kong learners. The Modern Language Journal, 87(2), 222-241. https://doi.org/10.1111/1540-4781.00187

Gavriilidou, Z., \& Petrogiannis, K. (2016). Language learning strategy use of English FL learners in Greek schools: The role of school type and educational level. International Journal of Research Studies in Language Learning, 5(4), 67-81. https://doi.org/10.5861/ijrsll.2016.1346

Griffiths, Carol. (2003). Language learning strategy use and proficiency. Doctoral dissertation, University of Auckland, Auckland, Australia.

Griffiths, C. (2013). The strategy factor in successful language learning. Bristol: Multilingual Matters.

Harkness, J. A., \& Schoua-Glusberg, A. (1998). Questionnaires in translation. ZUMA-Nachrichten Spezial, 3, 87-127.

Instituto Cervantes. (2006). Instituto Cervantes curriculum plan. Reference levels for Spanish [In Spanish]. Madrid: Biblioteca Nueva.

Johnson, K. R., \& Fan, M. Y. (1996). Bridging the technical gap: The problem of recoding the technical vocabulary of Chinese medium secondary students moving to English medium tertiary studies. Hong Kong: Chiu Ming Publishing Co. 
Assessing cognitive learning strategies: A global study of Spanish learners

Kambakis, P. (2016) Variables affecting choice of language learning strategies by Greek learners of English attending elementary school. In Z. Gavriilidou \& K. Petrogiannis (Eds.), Language learning strategies in the Greek setting: Research outcomes of a large-scale project (pp. 42-57). Kavala: Saita publications.

Kaylani, C. (1996). The influence of gender and motivation on EFL learning strategy use in Jordan. En Oxford, R. L. (Ed.), Language learning strategies around the world: Cross-cultural perspectives (pp.75-88). Honolulu: University of Hawai'i Press.

Kazamia, V. (2016) Gender and age impact on language learning strategy use: A study of Greek EFL learners. In Z. Gavriilidou \& K. Petrogiannis (Eds.), Language learning strategies in the Greek setting: Research outcomes of a large-scale project (pp. 76-100). Kavala: Saita publications.

Macaro, E. (2006). Strategies for language learning and for language use: Revising the theoretical framework. The Modern Language Journal, 90(3), 320-337. https://doi.org/10.1111/j.1540-4781.2006.00425.x

O'Malley, J. M., \& Chamot, A. U. (1990). Learning strategies in second language. Cambridge: Cambridge University Press. https://doi.org/10.1017/CBO9781139524490

Oxford, R. (1990). Language learning strategies: what every teacher should know. New York: Newbury House.

Oxford, R. (2013). Teaching and researching language learning strategies. New York: Routledge.

Oxford, R., \& Cohen, A. (1992). Language learning strategies: Crucial issues of concept and classification. Applied Language Learning, 3, 1-35.

Oxford, R. L., \& Nyikos, M. (1989). Variables affecting choice of language learning strategies by university students. Modern Language Journal, 73(3), 291-300. https://doi.org/10.1111/j.1540-4781.1989.tb06367.x

Platsidou, M., \& Sipitanou, A. A. (2014). Exploring relationships with grade level, gender and language proficiency in the foreign language learning strategy use of children and early adolescents. International Journal of Research Studies in Language Learning, 4(1), 83-96.

Rahimi, M., Riazi, A., \& Saif, S. (2008). An investigation into the factors affecting the use of language learning strategies by Persian EFL learners. Canadian Journal of Applied Linguistics (CJAL), 11(2), 31-60.

Rahman, A., Iqbal, Z., Waheed, W., \& Hussain, N. (2003). Translation and cultural adaptation of health questionnaires. Journal-Pakistan Medical Association, 53(4), 142-146.

Rodríguez Fuentes, G. (2009). Motivation, learning strategies and academic performance in ESO students [In Spanish]. Doctoral dissertation, Universidade da Coruña, la Coruña, Spain.

Rose, H. (2012). Reconceptualizing Strategic Learning in the Face of Self-Regulation: Throwing Language Learning Strategies out with the Bathwater. Applied Linguistics, 33(1), 92-98. https://doi.org/10.1093/applin/amr045

Tezcan, S., \& Deneme, S. (2016). A study on language learning strategy use of young Turkish learners. Journal of Language Teaching and Research, 7(1), 42-48. https://doi.org/10.17507/jltr.0701.05

Weinstein, C. E., Schulte, A. C., \& Hoy, A. W. (1987). Learning and study strategies inventory. Clearwater: H \& H Publishing.

World Health Organization (2010, November 5). Process of translation and adaptation of instruments. Retrieved from http://www.who.int 
Di Carlo, S.

Appendices

Table A.1

Descriptive Statistics for Classification Scale

\begin{tabular}{llllll}
\hline \multirow{2}{*}{ Item } & \multicolumn{1}{c}{ Activity } & \multicolumn{2}{c}{$\mathrm{n}$} & \multirow{2}{*}{$S D$} \\
\cline { 3 - 4 } & & valid & missing & & \\
\hline 01 & I take notes of the explanations from those I consider experts in Spanish. & 656 & 9 & 79.92 & 22.64 \\
02 & I write what I don't understand in my notebook. & 649 & 16 & 65.78 & 31.68 \\
03 & I mark what I don't understand in texts. & 649 & 16 & 72.08 & 27.25 \\
04 & I mark what I consider important in texts. & 651 & 14 & 78.03 & 25.54 \\
05 & When I want an example, I look for it in a book, web site, etc. & 651 & 14 & 70 & 28.54 \\
06 & When I don't understand something, I ask someone to explain it to me. & 658 & 7 & 72.31 & 25.65 \\
07 & When I am unsure, I consult learning materials. & 659 & 6 & 74.54 & 24.20 \\
08 & When I want to learn new contents, I look for them in the learning & 633 & 32 & 61.17 & 29.16 \\
& materials. & & & \\
09 & I copy what I consider to be important from the learning material word & 614 & 51 & 53.34 & 32.64 \\
& for word in my notebook. & & & & \\
10 & I ask for words I don't understand to be spelt. & 610 & 55 & 52.97 & 33.72 \\
11 & I use colors to highlight different parts of verbs in their conjugations. & 547 & 118 & 35.41 & 35.33 \\
12 & I analyze word endings. & 594 & 71 & 48.54 & 33.99 \\
13 & I analyze the beginning of words. & 570 & 95 & 43.49 & 31.87 \\
14 & I make tables for verbs, pronouns, etc. & 578 & 87 & 56.75 & 34.10 \\
\hline & Total & 8,719 & 591 & \\
\hline
\end{tabular}

Table A.2

Descriptive Statistics for Preparation Scale

\begin{tabular}{|c|c|c|c|c|c|}
\hline \multirow{2}{*}{ Item } & \multirow{2}{*}{ Activity } & \multicolumn{2}{|r|}{$\mathrm{n}$} & \multirow{2}{*}{$M$} & \multirow{2}{*}{$S D$} \\
\hline & & Valid & Missing & & \\
\hline 15 & I write new or difficult words or phrases. & 644 & 21 & 71.70 & 27.97 \\
\hline 16 & I read new or difficult words or phrases several times. & 644 & 21 & 70.26 & 26.49 \\
\hline 17 & I listen to new or difficult words or phrases several times. & 619 & 46 & 59.11 & 30.67 \\
\hline 18 & I say new or difficult words or phrases aloud several times. & 630 & 35 & 63.89 & 31.02 \\
\hline 19 & I mentally repeat new or difficult words or phrases. & 637 & 28 & 70.63 & 27.43 \\
\hline 20 & I memorize parts of films. & 530 & 135 & 38.50 & 33.96 \\
\hline 21 & I sing parts of songs. & 616 & 49 & 64.50 & 32.47 \\
\hline 22 & $\begin{array}{l}\text { I pronounce new sounds in isolation several times, separately from } \\
\text { the words. }\end{array}$ & 589 & 76 & 49.23 & 33.48 \\
\hline 23 & I pronounce words that have new sounds several times. & 586 & 79 & 53.88 & 33.22 \\
\hline 24 & I say rhymes or tongue twisters. & 511 & 154 & 27.59 & 29.11 \\
\hline 25 & I draw the meanings of new words. & 461 & 204 & 23.20 & 30.17 \\
\hline 26 & I mentally visualize an image of the meaning of new words. & 548 & 117 & 46.80 & 34.32 \\
\hline 27 & I look at the real object that a word represents to remember it better. & 538 & 127 & 41.19 & 33.62 \\
\hline 28 & $\begin{array}{l}\text { I look at an image, photo or drawing of the meaning of a word to } \\
\text { remember it better. }\end{array}$ & 538 & 127 & 43.07 & 34.51 \\
\hline 29 & I repeat examples of grammatical constructions. & 597 & 68 & 55.82 & 30.34 \\
\hline \multirow[t]{2}{*}{30} & $\begin{array}{l}\text { I read to familiarize myself with grammatical structures and } \\
\text { vocabulary. }\end{array}$ & 630 & 35 & 68.96 & 28.55 \\
\hline & Total & 9,318 & 1,322 & & \\
\hline
\end{tabular}


Table A.3

Descriptive Statistics for Association Scale

\begin{tabular}{|c|c|c|c|c|c|}
\hline \multirow{2}{*}{ Item } & \multirow{2}{*}{ Activity } & \multicolumn{2}{|c|}{$\mathrm{n}$} & \multirow{2}{*}{$M$} & \multirow{2}{*}{$S D$} \\
\hline & & Valid & Missing & & \\
\hline 31 & $\begin{array}{l}\text { I compare parts of words (prefixes, suffixes, roots) in Spanish with } \\
\text { parts of words in other languages. }\end{array}$ & 586 & 79 & 56.50 & 32.70 \\
\hline 32 & $\begin{array}{l}\text { I relate conjugations and verbs tenses in Spanish with verb forms in } \\
\text { other languages. }\end{array}$ & 597 & 68 & 59.97 & 30.45 \\
\hline 33 & I link what I learn to a context or situation. & 612 & 53 & 64.98 & 28.83 \\
\hline 34 & I link new words with images I know. & 539 & 126 & 50.17 & 32.71 \\
\hline 35 & I link words with sensations or feelings (cold, sadness...) & 520 & 145 & 41.26 & 33.00 \\
\hline 36 & $\begin{array}{l}\text { To learn sounds in Spanish, I think of similar sounds from other } \\
\text { languages that I know. }\end{array}$ & 560 & 105 & 48.18 & 35.06 \\
\hline 37 & $\begin{array}{l}\text { I think of Spanish words that have similar sounds to words in other } \\
\text { languages I know. }\end{array}$ & 573 & 92 & 53.71 & 33.49 \\
\hline 38 & $\begin{array}{l}\text { I think of Spanish words that are written in a similar way to words in } \\
\text { other languages I know. }\end{array}$ & 572 & 93 & 58.39 & 31.62 \\
\hline 39 & I make jokes with new words. & 491 & 174 & 32.35 & 32.81 \\
\hline 40 & When I come across unknown words, I look for their synonyms. & 605 & 60 & 60.44 & 30.03 \\
\hline 41 & I look for the definition of words I do not know. & 650 & 15 & 77.19 & 25.78 \\
\hline 42 & $\begin{array}{l}\text { In order not to use the same words, I learn others that have the same } \\
\text { meaning. }\end{array}$ & 621 & 44 & 63.21 & 28.32 \\
\hline 43 & $\begin{array}{l}\text { When I learn a Spanish word, I think about words in my language that } \\
\text { have equivalent meanings. }\end{array}$ & 637 & 28 & 73.29 & 27.61 \\
\hline 44 & I think about words with related meanings in a thematic area. & 571 & 94 & 50.53 & 31.68 \\
\hline 45 & I write new Spanish words along with their translation in my language. & 629 & 36 & 73.83 & 29.68 \\
\hline 46 & When I find a new word, I think about words with the same root. & 557 & 108 & 45.42 & 31.98 \\
\hline 47 & $\begin{array}{l}\text { I look for equivalents between sayings in Spanish and sayings or } \\
\text { proverbs in my mother tongue. }\end{array}$ & 576 & 89 & 54.45 & 32.93 \\
\hline \multirow[t]{2}{*}{48} & I invent stories using words that I want to learn. & 492 & 173 & \multirow[t]{2}{*}{27.73} & \multirow[t]{2}{*}{30.29} \\
\hline & Total & 10,388 & 1,582 & & \\
\hline
\end{tabular}

Table A.4

Descriptive Statistics for Elaboration Scale

\begin{tabular}{|c|c|c|c|c|c|}
\hline \multirow{2}{*}{ Item } & \multirow{2}{*}{ Activity } & \multicolumn{2}{|r|}{$\mathrm{n}$} & \multirow{2}{*}{$M$} & \multirow{2}{*}{$S D$} \\
\hline & & Valid & Missing & & \\
\hline 49 & I deduce the meaning of words from their use in different situations. & 623 & 42 & 67.07 & 28.39 \\
\hline 50 & I deduce grammatical rules and I make generalizations. & 581 & 84 & 52.07 & 30.42 \\
\hline 51 & I make mind maps, diagrams or outlines of what I have learned. & 511 & 154 & 38.60 & 33.91 \\
\hline 52 & I explain the content of learning aloud to myself. & 545 & 120 & 52.50 & 35.70 \\
\hline 53 & I explain what I know to another person. & 597 & 68 & 58.15 & 30.48 \\
\hline 54 & I ask myself reflective and critical questions about what I learn. & 548 & 117 & 47.45 & 31.52 \\
\hline 55 & $\begin{array}{l}\text { With another learner, we ask each other reflective questions about } \\
\text { new contents. }\end{array}$ & 515 & 150 & 47.62 & 32.90 \\
\hline 56 & I try to get the general idea of what I read. & 634 & 31 & 77.74 & 22.75 \\
\hline 57 & I write the key words of texts that I read. & 573 & 92 & 53.71 & 33.20 \\
\hline 58 & I compile and assimilate information from several sources to learn. & 558 & 107 & 58.69 & 30.64 \\
\hline 59 & I write explanations in my own words. & 598 & 67 & 64.98 & 29.91 \\
\hline 60 & I write summaries of what I read. & 555 & 110 & 48.78 & 33.83 \\
\hline 61 & I create my own material for studying and revising. & 601 & 64 & 64.89 & 32.95 \\
\hline \multirow[t]{2}{*}{62} & $\begin{array}{l}\text { I pay attention to everything that happens in conversations carried } \\
\text { out by other people. }\end{array}$ & 625 & 40 & 66.80 & 27.31 \\
\hline & Total & 8,064 & 1,246 & & \\
\hline
\end{tabular}


Di Carlo, S.

Table A.5

Descriptive Statistics for Transfer and Practice Scale

\begin{tabular}{llllll}
\hline \multirow{2}{*}{ Item } & \multicolumn{1}{c}{ Activity } & \multicolumn{2}{c}{$\mathrm{n}$} & \multirow{2}{*}{$M$} & $S D$ \\
\cline { 3 - 4 } & & Valid & Missing & \\
\hline 63 & I actively look for real situations to apply what I learn. & 583 & 82 & 60.61 & 30.41 \\
64 & I apply what I learn in real communication situations. & 609 & 56 & 68.06 & 28.27 \\
65 & I use what I learn only when I am sure that I am not going to make & 571 & 94 & 45.60 & 33.20 \\
& mistakes. & & & & \\
66 & I try to imitate people I consider to be experts & 614 & 51 & 71.71 & 29.14 \\
67 & I write down the conjugations of the most important or difficult & 596 & 69 & 63.74 & 33.70 \\
& verbs. & & & & \\
68 & I invent my own examples. & 545 & 120 & 49.60 & 32.54 \\
69 & I construct dialogues with myself. & 533 & 132 & 51.30 & 35.57 \\
70 & I do exercises immediately after seeing new topics. & 550 & 115 & 48.27 & 31.15 \\
71 & I mentally use what I learn in situations that I imagine. & 553 & 112 & 55.97 & 32.00 \\
72 & I chat in Spanish on Internet. & 553 & 112 & 53.46 & 37.48 \\
73 & I participate in face-to-face conversations. & 569 & 96 & 62.92 & 33.10 \\
74 & I ask someone who knows Spanish to correct me. & 616 & 49 & 70.94 & 30.32 \\
75 & I watch films with audio in Spanish and subtitles in my language. & 567 & 98 & 47.09 & 35.34 \\
76 & I watch films with audio in my language and subtitles in Spanish. & 512 & 153 & 27.57 & 34.11 \\
77 & I watch films with audio and subtitles in Spanish. & 569 & 96 & 58.87 & 36.86 \\
78 & I watch films with audio in Spanish and without subtitles. & 574 & 91 & 61.39 & 37.26 \\
79 & I listen to music in Spanish. & 635 & 30 & 74.84 & 30.49 \\
80 & I read aloud, without knowing the meaning of the text. & 562 & 103 & 47.27 & 35.17 \\
\hline & Total & 10,311 & 1,659 & & \\
\hline
\end{tabular}

